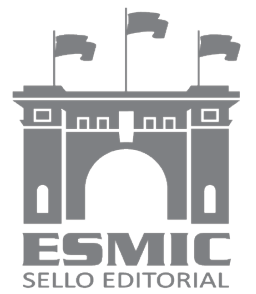

Revista Científica General José María Córdova

ISSN 1900-6586 (impreso), 2500-7645 (en línea)

Volumen 16, Número 23, julio-septiembre 2018, pp. 43-61

http://dx.doi.org/10.21830/19006586.304

Citación: Cuervo Ceballos, G. (2018, julio-septiembre). El crimen organizado transnacional como una amenaza híbrida para la Triple Frontera (Argentina, Paraguay y Brasil). Rev. Cient. Gen. José María Córdova, 16 (23), 43-61. DOI: http://dx.doi.org/10.21830/19006586.304

\title{
El crimen organizado transnacional como una amenaza híbrida para la Triple Frontera (Argentina, Paraguay y Brasil)
}

Sección: Estudios MiLITARES

Artículo de investigación científica y tecnológica

Geraldine Cuervo Ceballos*

Universidad Militar Nueva Granada

Transnational organized crime as a hybrid threat to Argentina, Paraguay and Brazil's Triple Frontier

O crime organizado transnacional como uma ameaça híbrida à Tríplice Fronteira da Argentina, Paraguai e Brasil

Le crime organisé transnational comme une menace hybride à la Triple Frontière de l'Argentine, Paraguay et Brésil

Recibido: 14 de febrero de 2018 • Aceptado: 24 de junio de 2018

* https://orcid.org/0000-0001-7935-5768 - Contacto: U0901937@unimilitar.edu.co 
Resumen. El poder de las organizaciones criminales han permeado las instituciones con el denominado crimen organizado transnacional, un fenómeno que se apoya en la apertura comercial, el flujo de bienes y personas, el crecimiento económico, el desarrollo tecnológico y el tránsito de agentes no estatales que comercializan productos ilícitos. Estas "empresas del crimen" representan un desafío para el Estado y son una amenaza visible para el corredor fronterizo entre Argentina, Paraguay y Brasil, así como para los demás países de la región. Por medio de este escrito, se identifican los factores más destacados que han contribuido al asentamiento de dichas redes criminales en la Triple Frontera, por ejemplo, el crecimiento poblacional, las características geográficas que dificultan el control de la zona, las escasas iniciativas conjuntas, la ausencia de control y de políticas globales y el carácter híbrido de estas organizaciones. El método de investigación aplicado fue cualitativo, explicativo, analítico y documental.

Palabras clave: amenazas híbridas; crimen organizado transnacional; seguridad regional; Triple Frontera.

\begin{abstract}
The power of criminal organizations has permeated the institutions with the so-called transnational organized crime, a phenomenon that finds support on economic openness, economic growth, technological development, and the flow of goods and people and transit of non-state agents that commercialize illicit products. These "companies of crime" represent a challenge for the State and are a visible threat to the border corridor between Argentina, Paraguay, and Brazil, as well as to the other countries of the region. In this document, the most outstanding factors that have contributed to the settlement of these criminal networks in the Triple Frontier are identified, for example, the population growth and geographical characteristics that hinder the control of the area, the scarce joint initiatives, the lack of control and global policies, and the hybrid nature of these organizations. The applied research method was qualitative, explanatory, analytical, and documentary.
\end{abstract}

Keywords: hybrid threats; regional security; transnational organized crime; Triple Frontier.

Resumo. $\mathrm{O}$ poder das organizações criminosas permeiam as instituiçôes com o chamado crime organizado transnacional, fenômeno que se baseia na abertura comercial, no fluxo de bens e pessoas, no crescimento econômico, no desenvolvimento tecnológico e no trânsito de agentes não estatais que comercializam produtos ilícitos. Essas "empresas criminosas" representam um desafio para o Estado e são uma ameaça visível ao corredor fronteiriço entre Argentina, Paraguai e Brasil, bem como aos demais países da região. Neste documento, os fatores mais destacados que contribuíram para o estabelecimento dessas redes criminosas na Tríplice Fronteira são identificados, por exemplo, o crescimento populacional, as características geográficas que dificultam o controle da área, as escassas iniciativas conjuntas, a falta de controle e políticas globais e a natureza híbrida dessas organizaçóes. O método de pesquisa aplicada foi qualitativo, explicativo, analítico e documental.

Palavras-chave: ameaças híbridas; crime organizado transnacional; Fronteira tripla; segurança regional.

Résumé. Le pouvoir des organisations criminelles ont infiltré les institutions avec la dénommée criminalité transnationale organisée, un phénomène basé sur l'ouverture commerciale, la circulation des biens et des personnes, la croissance économique, le développement technologique et le transit des acteurs non étatiques qui commercialisent produits illicites. Ces «sociétés criminelles» représentent un défi pour l'État et constituent une menace visible pour le corridor frontalier entre l'Argentine, le Paraguay et le Brésil, ainsi que pour les autres pays de la région. Dans ce document, les facteurs les plus remarquables qui ont contribué à l'établissement de ces réseaux criminels dans la Triple Frontière sont identifiés, par exemple, la croissance de la population, les caractéristiques géographiques qui entravent le contrôle de la zone, la carence de contrôle et les politiques mondiales et la nature hybride de ces organisations. La méthode de recherche appliquée était qualitative, explicative, analytique et documentaire.

Mots-clés : criminalité transnationale organisée ; menaces hybrides ; sécurité régionale ; Triple Frontière. 


\section{Introducción}

El poder de las organizaciones criminales en la Triple Frontera (Argentina, Paraguay y Brasil) ha ido evolucionando, pues inicialmente solo podían mantener un control local, pero luego, a medida que fueron creciendo, lograron un control territorial más intensivo en las zonas del interior de estos Estados, para después escalar a un escenario de transnacionalización del delito con dominio de extensas zonas transfronterizas, como sucede en la actualidad.

La identificación de los grupos criminales no era sencilla, puesto que combatir su existencia no era de interés prioritario para los gobiernos, ya que no representaba una amenaza directa para su estabilidad. Por esta razón, el crimen organizado transnacional comenzó a asentarse en las zonas grises - los espacios vacíos ${ }^{1}$ y olvidados por el gobierno-- con el fin de expandirse y lograr una red criminal poderosa transnacional.

Estas organizaciones criminales permean estructuras institucionales para así controlar los pasos fronterizos y afianzar su poder. Por esto, es necesario precisar, antes de entrar a caracterizar la zona trifronteriza, lo que se entiende por frontera. En palabras de Pereira (2016), "La frontera, a su vez, puede ser un factor de integración, en la medida en que sea una zona de interpretación mutua y de constante manipulación de estructuras sociales, políticas y culturales distintas" (p. 13, traducción propia).

Argentina, Paraguay y Brasil, a partir de su experiencia común para enfrentar la amenaza y combatir los escenarios que han permitido la globalización y la liberalización de las fronteras, evidencian insuficiencia en el imperio de la ley, lo cual, sumado a la corrupción, incrementa el problema del control territorial. El crimen organizado transnacional (COT) en la Triple Frontera ha evolucionado y crecido a tal punto que los Estados buscan las herramientas necesarias para combatir los desafíos de seguridad, conformando un espacio de interés y de estudio para minimizar sus efectos. Por su parte, La declaración sobre seguridad en las Américas de 2003 describe que las amenazas a la seguridad se han ido ampliando:

El concepto de seguridad, que en un momento se enmarcaba principalmente en términos militares convencionales, hoy ha debido ampliar su marco de referencia y tener en cuenta una variedad de amenazas: terrorismo internacional, tráfico de drogas y armas ilegales, trata de personas, lavado de dinero, corrupción institucional y crimen organizado. En algunos países la pobreza, las enfermedades y la degradación del medio ambiente contribuyen al deterioro de la seguridad humana. (Organización de Estados Americanos, 2003, p. 106)

$1 \quad$ Los espacios vacíos o zonas grises se caracterizan por ser fronteras de gran longitud, que representan debilidades a causa de los problemas de seguridad y defensa por la escasa vigilancia y el incremento del crimen organizado transnacional (COT). 
Dentro del análisis de los tres Estados, se aborda una problemática coyuntural que afecta a la seguridad local y regional de la Triple Frontera: una amenaza a la seguridad regional que afecta esferas como la estabilidad política, económica, y social. La investigación es pertinente dados los niveles de violencia, índices de homicidio y conflictividad que caracteriza los corredores fronterizos a analizar, y también dado que no se evidencia una disminución real del COT, a pesar de las estrategias que estos gobiernos han implementado.

El presente artículo plantea la siguiente pregunta de investigación: ¿Por qué las redes criminales se han asentado en el corredor fronterizo de Argentina, Paraguay y Brasil? Con una hipótesis inicial, se señala que la confluencia de factores como el crecimiento poblacional, las características geográficas que dificultan el control espacial de la zona, las escasas iniciativas conjuntas, la ausencia de control y de políticas globales, además del carácter híbrido de estas organizaciones, han contribuido al asentamiento de las redes criminales en la Triple Frontera.

Para el análisis se demuestra, en primer lugar, la caracterización general sobre la región, en la cual se describen las causas que animaron a que las redes criminales se establecieran allí. Luego, se presenta una contextualización sobre las amenazas híbridas, en la misma línea. En el estudio del crimen organizado transnacional como una amenaza híbrida en la Triple Frontera, se describen los actores delictivos y su modus operandi y, a continuación, las consecuencias que se derivan del débil control estatal —que significan un desafío para la gobernanza local y regional—. Finalmente, se busca promover algunas reflexiones que nutren el artículo de investigación y permiten un medio para enfrentar la amenaza latente en la zona. La investigación es de tipo cualitativa, explicativa y con vocación de ser analítica y documental.

\section{Características de la región}

La Triple Frontera está conformada por los ríos Iguazú y Paraná, más las ciudades de Foz de Iguaçu, Ciudad del Este y Puerto Iguazú ${ }^{2}$. Estas ciudades comienzan a cobrar importancia dado su crecimiento vertiginoso, el cual está ligado a tres importantes obras de infraestructura: el puente internacional de la Amistad (creado en 1965), el puente internacional Tancredo Neves (creado en $1985^{3}$ ) y la represa hidroeléctrica de Itaipú creada en 1976 e inaugurada en el año de 1986, obras que tenían como objetivo la integración fronteriza y el crecimiento poblacional. Como lo señala Fogel, "la población del territorio [Triple Frontera] pasó de 60.000 habitantes al comienzo de la construcción de la

2 Ciudad del Este posee una población de 281.422, según el censo de 2012; Foz de Iguazú, 263.915 personas habitantes, según el censo del 2016; y Puerto Iguazú, una población de 41.062 personas, según el censo de 2010 (Argentina, Instituto Nacional de Estadística y Censos [Indec], 2017; Brasil, Instituto Brasileńo de Geografía y Estadística [IBGE], 2017; Paraguay, Dirección General de Estadística, Encuestas y Censos [DGEEC], 2016).

3 El puente internacional de la Amistad tiene una longitud de 552 metros y dos carriles para cruzar la frontera hacia Brasil desde Paraguay, mientras que el puente internacional Tancredo Neves, que conecta Brasil y Argentina, tiene una longitud de 482 metros, con una menor circulación. 
represa de Itaipú, a 700.000 habitantes en el 2001” (2008, p. 271). Estas construcciones ayudaron al crecimiento poblacional y, a su vez, a la comunicación en la región, como se evidencia en la tabla 1.

Tabla 1. Crecimiento de la población en ciudades fronterizas de la región

\begin{tabular}{ccccccc}
\hline & \multicolumn{2}{c}{ Ciudad del Este } & \multicolumn{2}{c}{ Foz de Iguaçu } & \multicolumn{2}{c}{ Puerto Iguazú } \\
\cline { 2 - 6 } Año & Población & $\begin{array}{c}\text { Crecimiento } \\
\text { entre periodos } \\
(\%)\end{array}$ & Población & $\begin{array}{c}\text { Crecimiento } \\
\text { entre periodos } \\
(\%)\end{array}$ & Población & $\begin{array}{c}\text { Crecimiento } \\
\text { entre periodos } \\
(\%)\end{array}$ \\
\hline $1970 / 2$ & 26.485 & & 33.966 & & 7.122 & \\
$1980 / 2$ & 62.328 & $135,30 \%$ & 136.321 & $301,30 \%$ & 9.151 & $28,50 \%$ \\
$1990 / 2$ & 133.881 & $114,80 \%$ & 190.115 & $39,50 \%$ & 28.148 & $207,60 \%$ \\
$2000 / 2$ & 223.350 & $66,80 \%$ & 258.368 & $35,90 \%$ & 31.371 & $11,50 \%$ \\
2005 & 225.000 & $0,70 \%$ & 301.409 & $36,70 \%$ & 33.361 & $6,30 \%$ \\
\hline
\end{tabular}

Fuente: elaboración propia con datos de Iniciativa para la Integración de la Infraestructura Regional Suramericana [IIRSA], (2005).

Asimismo, esta región es rica en recursos naturales. Muestra de ello es el Acuífero Guaraní, reserva subterránea de agua dulce de $1.200 .000 \mathrm{~km}^{2}$, de cuya extensión el 71 $\%$ se encuentra bajo suelo brasileño, el $19 \%$ bajo suelo argentino y el $6 \%$ bajo Paraguay (Giménez \& Montenegro, 2010, p. 8).

Las tres ciudades que se encuentran junto a la Triple Frontera forman un territorio de $2.500 \mathrm{~km}^{2}$, y han recibido por años una ola de migrantes, principalmente libaneses por la guerra civil de 1980, así como comunidades árabes (desde el siglo XX), población siria y china, por lo cual es una zona pluriétnica y multicultural. En la figura 1 se visualiza la unión del río Paraná con el río Iguazú, atravesada por el puente Tancredo Neves y el puente de la Amistad. Esta infraestructura física permitió el gran flujo de personas que se transporta a diario hacia las tres ciudades, las cuales van en búsqueda de turismo comercial y turismo de naturaleza.

Por otro lado, los que se dirigen a Ciudad del Este van en búsqueda de productos electrónicos, perfumería, cigarrillos, electrodomésticos, alimentos y bebidas, pero también de armas. Estos productos, a pesar del control de las autoridades aduaneras, pasan diariamente sin mucha restricción por el puente de la Amistad. Los productos que pasan con poca restricción y, además, libres de pago de impuestos representan el $30 \%$ de la economía paraguaya ${ }^{4}$. Igualmente se benefician comerciantes brasileros y argentinos al realizar la llamada "triangulación" (Traslaviña, 2014).

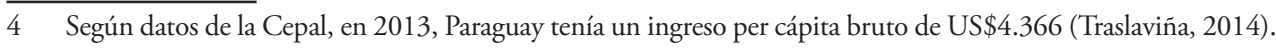


La magnitud del movimiento comercial en la región conlleva que gran parte del comercio sea controlado por inmigrantes taiwaneses, chinos, coreanos y libaneses, que ven una oportunidad en ese negocio tan lucrativo de etiquetar sus productos como originarios de Estados Unidos o Japón. Se trata de una zona receptiva al gran flujo de personas y mercancías, donde confluyen tanto turistas como comerciantes y traficantes, y como lo explica la periodista del New York Times, Diana Jean, "Si alguna vez hubo un monumento a la libertad de empresa y la ausencia de regulación gubernamental, es Ciudad del Este donde el 90 por ciento de lo que se vende es falso" (Osorio, 2015, p. 17).

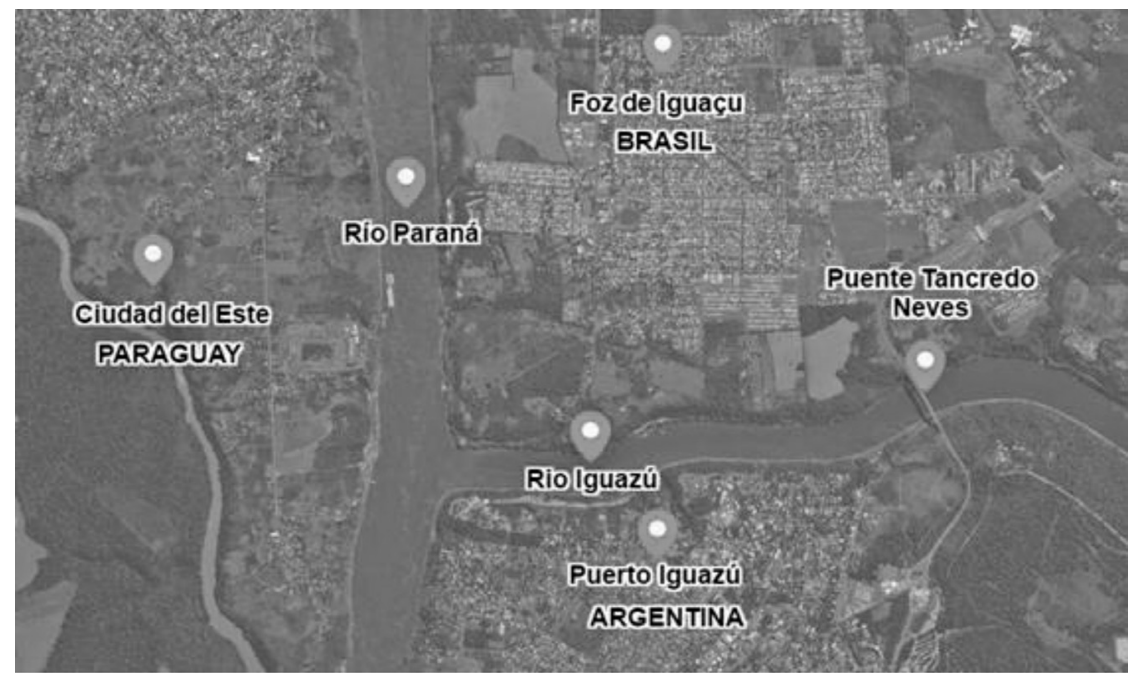

Figura 1. La región de la Triple Frontera.

Fuente: elaboración propia a partir de MapHub.

Por el puente de la Amistad (figura 2) transitan en promedio 18.500 vehículos y 20.000 peatones a diario, que circulan por la ruta internacional VII (PY) y la BR-277 (BR), que conectan a Paraguay con Brasil. Tal cantidad de tráfico, como lo explica Rabossi (2014), ocasiona que los controles de los agentes aduaneros se reduzcan a simples "vistazos" o, en llegados casos, las personas acudan a coimas (sobornos) para poder pasar su mercancía, legal o ilegal, por el puente. Menos del $10 \%$ de los equipajes que circulan en los puestos de control son revisados (Bartolomé, 2002). Sin embargo, no es sencillo organizar semejante cantidad de gente y de vehículos sin generar inconvenientes. Puede que esto propicie una tendencia al traspaso de mercancía ilegal, pero para regular el 90 $\%$ restante, debe haber mayor inteligencia policial y controles integrados. El movimiento a través del puente Tancredo Neves tiene un tráfico menor, pues moviliza alrededor de 5.040 vehículos en promedio diariamente, lo cual da pie a mayores controles aduaneros y policiales, aunque muchas veces también resulta insuficiente. 


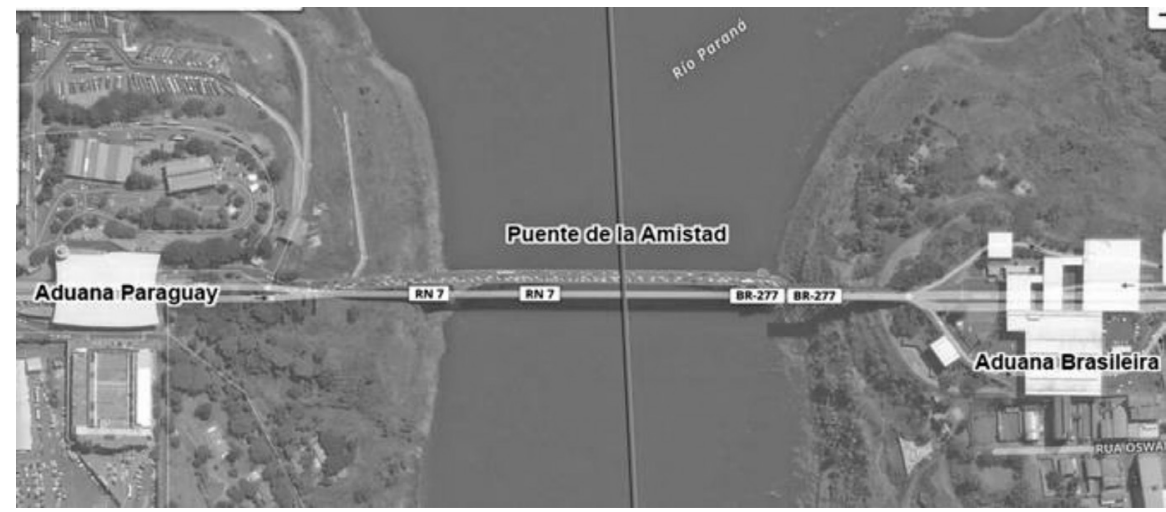

Figura 2. Tránsito del puente de la Amistad.

Fuente: elaboración propia a partir de MapHub.

Existe una transnacionalización de las empresas criminales en la frontera entre Brasil, Argentina y Paraguay. Dichas organizaciones pujan por el control de espacios estratégicos $y$ trabajan tanto internamente como en conjunto con otras organizaciones criminales para facilitar el tráfico de productos, el contrabando y la corrupción salgan victoriosos y para que los funcionarios corruptos se favorezcan de este entramado criminal. Esto representa una de las más graves problemáticas que afecta a la zona, fenómeno que se maximiza al tener en cuenta el crecimiento poblacional y cómo los grupos criminales sobrepasan las capacidades de la acción estatal. Asimismo, con la complicidad de los agentes aduaneros y los policías corruptos, las redes criminales pueden traspasar de manera subrepticia su mercancía tanto de día como de noche, por medios aéreos, terrestres y fluviales.

De la misma forma, la Triple Frontera fue foco de los lentes cuando se supuso que estos grupos financiaban al partido político de Hezbolá, sin embargo, a pesar de los rumores, no se ha podido demostrar que sea fuente real de financiación de células terroristas ${ }^{5}$. Se perpetraron ataques a la Embajada de Israel en Argentina en 1992 y a la Asociación Mutual Israelita Argentina en 1994, y las organizaciones criminales se fortalecieron luego de los ataques a las torres gemelas en Estados Unidos el 11 de septiembre de 2001. A pesar de esto, nunca hubo evidencia suficiente que demostrara la conexión terrorista entre Hezbolá o Al Qaeda y las bandas criminales de la Triple Frontera.

[Se] blanquean enormes sumas de dinero provenientes del narcotráfico, el contrabando y el tráfico de armas, se evaden impuestos, y se envían remesas, en cuestión de segundos, a casi cualquier parte del mundo, facilitando la labor de quienes emprenden actividades ilícitas, y haciendo plausible la tesis del financiamiento al terrorismo. (Bello, 2013)

5 El crimen organizado transnacional se diferencia del terrorismo porque su objetivo no es ideológico (aunque para alcanzar sus objetivos puede perseguir algunos fines políticos). Tampoco busca el poder político en sí, lo que busca es tener, en un contexto de estabilidad, formas de influencia que le permitan la impunidad para desarrollar su acción (Rojas, 2016). 
Por medio de estas conexiones, el desafío para el hemisferio se convierte en una realidad, y a su vez facilita el asentamiento de dichos grupos criminales a través de los espacios grises o donde el control estatal no logra llegar.

\section{Amenazas híbridas}

Durante décadas, los conflictos a nivel mundial estuvieron enmarcados por amenazas tradicionales que afectaban la seguridad de los Estados, las cuales eran llamadas conflictos interestatales $^{6}$ e iban en busca de poder territorial y expansión geopolítica. Sin embargo, no fue sino hasta finalizada la Guerra Fría y con la entrada de la globalización que se evidenció claramente una nueva reconfiguración del poder, la diversificación de los instrumentos de guerra y la regulación de la violencia organizada ${ }^{7}$.

El mundo ha entrado en una era de conflictos intraestatales, los cuales afectan directamente la paz y la seguridad internacional; se pasó de tener conflictos étnicos o civiles a tener una problemática regional conocida como crimen organizado transnacional. Por medio de este fenómeno, la existencia de grupos insurgentes y su supervivencia, atada al efecto de la globalización, llevaron a desarrollar su accionar a través de medios tecnológicos avanzados, situación que agrava el desmantelamiento de las organizaciones, amenazas múltiples que no son de fácil identificación, así como tampoco su actuar delictivo y sus finalidades criminales. Al existir multitud de actores —estatales y no estatales—, es más difícil su reconocimiento y su judicialización. Esto conlleva a una oleada de violencia continua y una población civil cada vez más afectada, puesto que el hibridismo de su naturaleza y la asimetría, cada vez más dominantes en este tipo de conflictos, son parte esencial de su proceder.

El padre del conflicto híbrido, Frank Hoffman, indica que la coexistencia de armamento, tácticas y combatientes es muy heterogénea, lo que genera una afectación mayor en aquellos Estados débiles institucionalmente, corruptos o "Estados mafia", como los denomina Naím (2012). Dado que las partes que se enfrentan son desiguales en muchos niveles (tecnológico, armamentista, capacidad logística, acceso a recursos, nivel de instrucción y adiestramiento), estas recurren a estrategias y tácticas de combate muy diferentes.

En definitiva, puede tratarse de un combate convencional con tácticas insurgentes. Frank G. Hoffman lo define como cualquier adversario que, de manera simultánea y adaptativa, emplea una mezcla de armas convencionales, tácticas irregulares, terrorismo y comportamiento criminal en el espacio de batalla para alcanzar sus objetivos políticos. (Hoffman, 2009).

6 Esta denominación tiene su origen en razones de orden económico, social o étnico en escenas que tenían lugar entre dos o más Estados.

7 Instrumentos que Mary Kaldor (2001) acuña para el inicio de las nuevas guerras.

8 Por Estados mafia se entienden aquellos países en los que el Estado controla y usa grupos criminales para promover y defender sus intereses nacionales y los intereses particulares de una élite de gobernantes (Naím, 2012). 
No se logra captar la complejidad, naturaleza e implicaciones de estas nuevas modalidades de lucha que parecían combinar el empleo de métodos y medios característicos de la guerra irregular con acciones convencionales limitadas de enorme eficacia; que reunían, además, el armamento más sencillo con algunos de los más avanzados sistemas de armas y sofisticados sistemas de mando, control, comunicaciones e inteligencia (Guillem, 2014). Es allí donde hay que atacar el flagelo y asegurar la paz y seguridad de los ciudadanos, así como estabilizar el sistema internacional frente a las amenazas existentes y las que se avecinan.

\section{El COT como una amenaza híbrida en la Triple Frontera}

Los grupos criminales que se asentaron en la región trifronteriza tenían el objetivo de lucrarse, de obtener dinero con modos "legales" o ilegales, y la Triple Frontera tenía todas las características necesarias para que el proceso del $\mathrm{COT}^{10}$ se consolidara y aumentara a través de los años.

Las redes criminales empezaron a consolidarse en función de grupos criminales chinos (como Fuk Ching, Big Circle Boys, Flying Dragons, Tai Chen y Pac Lun Fu) y familias mafiosas (como Ming y Sung I), lo cuales llegaron de China en 1980. Estas redes acentuaron su presencia en Ciudad del Este, cuando el gobierno paraguayo promovió la inmigración China con el fin de impulsar actividades comerciales en la región (Calderón, 2007, 6-15).

De acuerdo con el pronunciamiento en 2001 del diputado uruguayo Alberto Scavarelli, exprosecretario de la Presidencia de la República especializado en el combate de diversas formas de delito internacional, "en esa localidad convergen las estructuras delictivas más importantes a nivel internacional: la Yakuza japonesa, carteles colombianos y mexicanos, las mafias nigerianas y la propia mafia rusa” (Bartolomé, 2002, p. 63).

Los grupos criminales que se asentaron allí se especializaron en el contrabando de productos electrónicos, tráfico de drogas, de personas y transferencias de dinero. Esto se refleja en las cadenas de centros comerciales, pues son ellos y los brasiguayos ${ }^{11}$ quienes reciben las mayores ganancias del vertiginoso crecimiento en la Triple Frontera o, mejor dicho, del turismo de compras en Ciudad del Este. Utilizan la legalidad y ocultan en los

9 El lavado de dinero les permitió legalizar sus actividades criminales, por medio de juegos de azar o inversiones inmobiliarias. El blanqueo por medio del circuito financiero permitió que se legalizaran los dineros mal habidos (Bartolomé, 2002, pp. 66-70).

10 En la Convención de las Naciones Unidas contra la Delincuencia Organizada Transnacional se entiende por grupo delictivo organizado un grupo estructurado de tres o más personas que existe durante cierto tiempo y actúa concertadamente con el propósito de cometer uno o más delitos graves, con miras a obtener, directa o indirectamente, un beneficio económico u otro beneficio de orden material (Convención de Palermo, 2000). Estos grupos presentan un espectro de actividades tales como el narcotráfico, el tráfico ilícito de migrantes, la trata de personas, el lavado de dinero, el tráfico ilícito de armas de fuego y otras. Sin embargo, esta categoría no responde a lo que significa crimen organizado transnacional, dado que no hay una definición precisa del fenómeno, sino una variedad de asociaciones por parte de la comunidad académica.

11 Inmigración brasileńa en Paraguay, una de las más numerosas. 
escombros la ilegalidad. La figura 3 muestra las rutas de tráfico de droga de Paraguay hacia Brasil, donde la Triple Frontera sirve para las actividades delictivas de Pedro Juan Caballero (ciudad de Paraguay), ya que por esta zona la producción de cannabis sale hacia Argentina, Chile y Uruguay.

De la misma forma, con el fin de expandirse y lograr una red criminal poderosa transnacional comenzaron a aplicar medidas híbridas, lo cual se evidencia en el ataque contra la sede Prosegur de seguridad privada en Ciudad del Este (Paraguay). Este hecho se desarrolló en la madrugada del 24 de abril de 2017, por un grupo de aproximadamente de 50 hombres con armamento pesado y explosivos, quienes por medio de una estructura de mando, control y comunicaciones lograron hurtar seis millones de dólares. Para realizar la huida y evitar a las fuerzas de seguridad local, incendiaron vehículos repletos de municiones para luego dirigirse a la zona de frontera (Rivas, 2017).

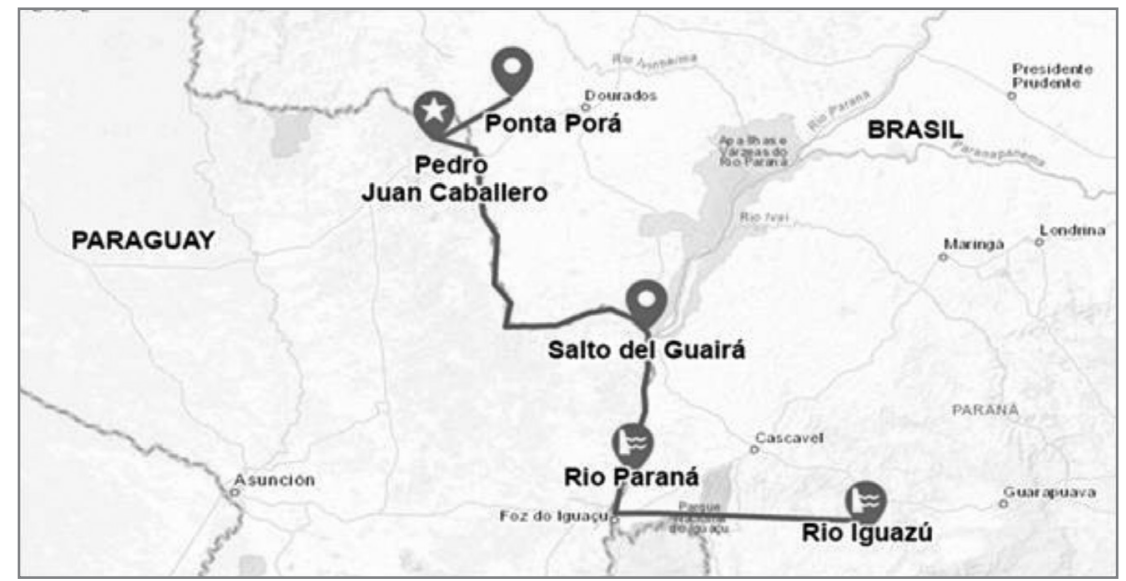

Figura 3. Rutas de tráfico de drogas de Paraguay-Paraná.

Fuente: elaboración propia con datos de Dreyfus (2005), Lynn (2011), 7 toneladas... (2016), Secuestran 7 toneladas... (2016) y La ruta de la droga... (2016).

Adicionalmente y aunque en menor medida, se ha evidenciado la presencia de carteles mexicanos y carteles colombianos, así como de mafias rusas y libanesas (Bartolomé, 2002). El Primer Comando Capital y el Comando Vermelho, surgidos en Brasil —uno en Río de Janeiro y otro en São Paulo—, datan de 1990 y 1970 respectivamente. Son grupos que han traído el terror a la Triple Frontera, que han provocado muertes e inestabilidad en la región por control de territorio, de rutas de tráfico y de venganza.

"Amambay ${ }^{12}$ es el preferido de miembros del Comando Vermelho y del PCC por nuestra frontera seca de 400 kilómetros", denunció el senador Roberto Acevedo, titular

12 Amambay, cuya capital es Pedro Juan Caballero, hace parte de los 17 departamentos que conforma la República del Paraguay. 
del Congreso Nacional de Pedro Juan Caballero. Es allí donde "realizan sus actividades con total normalidad y liquidando a quienes se les ponga enfrente", añadió. Esas bandas controlan los miles de toneladas de marihuana que son enviadas a Brasil, Argentina y Chile, además de ser el corredor de cocaína que llega de Colombia, Bolivia y Perú, que pasa a Brasil y de allí a Europa (Pérez, 2017). En palabras de este mismo autor "Pedro Juan Caballero, la ciudad paraguaya que se convirtió en la capital narco de Sudamérica”.

Por lo tanto, La Triple Frontera se convierte en punto clave para los movimientos criminales que realizan a diario las organizaciones por medio del tráfico de drogas, armas y contrabando de otros productos. Los casos son múltiples y se centran en zonas como Pedro Juan Caballero, ciudad paraguaya que limita con la ciudad de Ponta Porã en la frontera de estado de Mato Grosso do Sul.

El epicentro del crimen organizado se encuentra en Paraguay, lo que se explica dado que históricamente sus instituciones de gobierno han sido frágiles, ligadas a la corrupción y al soborno, y su figura se reduce a tan solo el presidente, además de no ser perdurables en el tiempo. Los mecanismos de control en la zona han sido insuficientes, como se ha recalcado a lo largo del escrito; todo esto se conflagra y crea un Paraguay culturalmente corrupto y con vacíos de poder. La figura 4 refleja la ruta de tráfico de droga desde Paraguay hacia Argentina, donde el foco va de Pedro Juan Caballero hasta el Río Paraná Guazú ${ }^{13}$.

Estas características se acentuaron durante la dictadura del general Alfredo Stroessner, "El Stronato" (1954-1989), "un periodo de 'corrupción feudalizada' en la cual el 'hombre fuerte' en el gobierno distribuía 'feudos' de negocios legales e ilegales entre sus funcionarios (gobernadores militares y civiles)" (Dreyfus, 2005, p. 14).

La estabilidad internacional se ha visto afectada por el modus operandi de las redes criminales en el área con centro en Paraguay, un país sin salida al mar. Respecto al delito del contrabando, a pesar de los intentos de regulación internacional, este se encuentra presente y en aumento:

Puertos de Paranaguá (estado de Paraná) y Santos (Estado de Sáo Paulo). Ambos puertos son los dos más activos de Brasil y según las prácticas y regulaciones internacionales los containeres en tránsito hacia un tercer país no pueden ser abiertos hasta llegar a destino, a menos que haya una orden judicial al respecto. El tránsito de containeres en el corredor Paranaguá-Foz de Iguazú (ambas ciudades están a aproximadamente 600 $\mathrm{km}$ conectadas por la autopista BR 373) es utilizado según fuentes consultadas para el tráfico de armas y municiones que luego son reingresadas a Brasil desde Ciudad del Este por vía fluvial, terrestre y aérea. (Dreyfus, 2005, pp. 15-33)

13 El 30 de diciembre de 2016, un buque mercante que atravesó el Río Paraná Guazú (Paraguay-Argentina), transportaba 7 toneladas de marihuana a bordo, uno de los golpes más duros a la ilegalidad por parte de la Prefectura Naval de Argentina (Secuestran 7 toneladas..., 2016). 


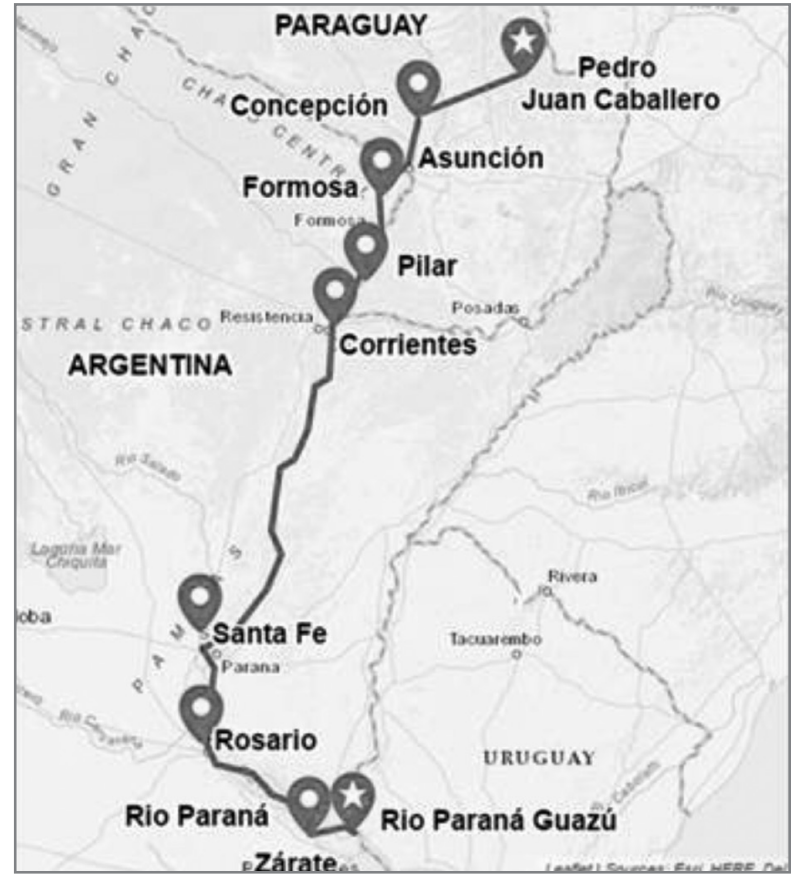

Figura 4. Rutas de tráfico de drogas de Paraguay a Argentina.

Fuente: elaboración propia a partir de datos de (La ruta de la droga..., 2016).

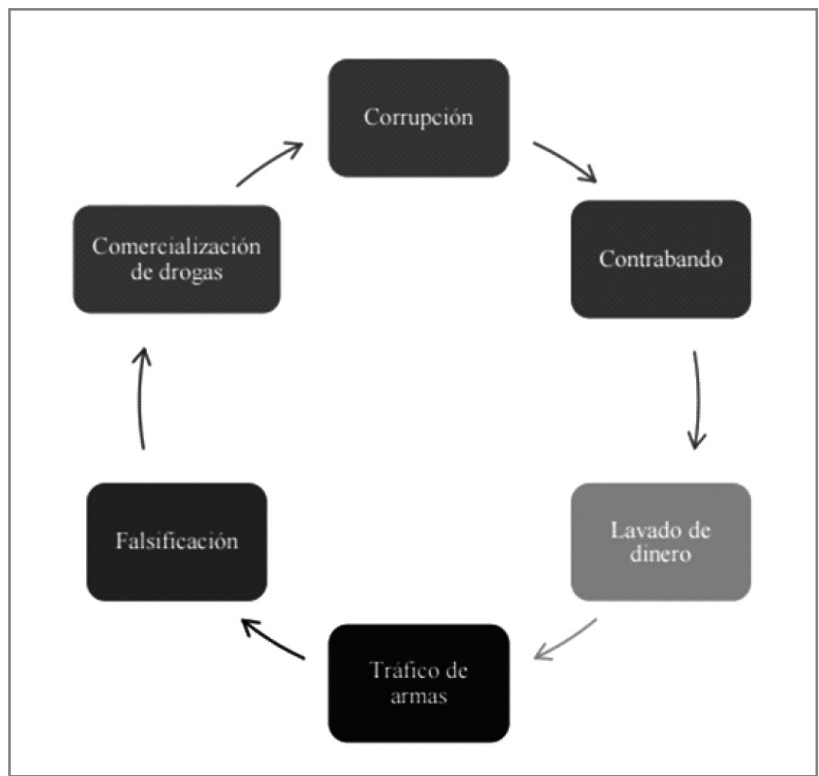

Figura 5. El modus operandi en la Triple Frontera.

Fuente: elaboración del semillero Seguridad, Violencia y Paz de la UMNG. 
Como muestra la figura 5, el modus operandi es un círculo vicioso, con varios beneficios para el COT, entre los cuales se mencionan los más importantes a continuación:

- La corrupción (el "cáncer" de América Latina), una de las actividades más frecuentes, con más ganancias y con mayor impunidad. Todo el proceso delictivo ha logrado perpetrase en el tiempo y obtener un gran alcance sin visos de detenerse, dados los abundantes y rentables ingresos ilegales que reciben tanto grupos ilícitos como los órganos de control y vigilancia de la zona fronteriza (desde quienes controlan las aduanas y vigilan temas migratorios hasta los altos mandos). Asimismo, si se logra desmantelar las redes profundas de corrupción, el círculo vicioso de las actividades ilegales se romperá: el modus operandi es tan incierto que no podrá mantenerse sin la ayuda de los entes de control.

- El contrabando. Es la actividad más lucrativa. De por sí beneficia principalmente a Paraguay (Ciudad del Este) y a Brasil (Foz de Iguazú), que tienen un paso directo por medio del puente de la Amistad y por el puente Tancredo Neves, unos pasos transitables de gran facilidad, dada la escasa vigilancia de los policías $\mathrm{o}$ agentes aduaneros.

Según datos de la Cepal (Traslaviña, 2014), en 2013 Paraguay tenía un ingreso per cápita bruto de US\$4.366. Así, de acuerdo con este autor, "mientras en Brasil la carga tributaria total es de 25,5\%, en Paraguay es de 13,5\%. A su vez, mientras en Brasil el IVA es de 20,5\%, en Paraguay este mismo tributo es de solo $10 \%$. Y en el caso particular del impuesto al tabaco y cigarrillos, en Brasil es de 62,1\%, pero en Paraguay es de solo $12 \%$.

Esta actividad se ha incrementado en medios fluviales, aéreos y terrestres. Los grupos delictivos operan en la Triple Frontera de día y de noche, pagando coimas, si se requiere, para pasar la mercancía que será transportada a estos tres países y a ciudades con escasos controles migratorios (productos que provienen de Asia y China, entre otros países, con marcas reconocidas falsificadas).

- Cuando se trata de legalizar las actividades delictivas, más precisamente, sus ingresos, el lavado de dinero es la opción, por medio del blanqueo en el circuito financiero: compra de inmuebles o juegos de azar, con el dinero proveniente de las actividades ilícitas (el tráfico de armas, drogas, personas y, una de las más comunes y con mayor popularidad en los últimos meses, la evasión impositiva. Los grupos delictivos también hacen uso de "paraísos fiscales" para esconder sus ganancias, pues estos no son estrictamente usados por los ladrones "de cuello blanco".

- El tráfico de armas. Esta actividad se ha convertido en una de las más comunes en zonas permeadas por el crimen organizado y es también un círculo vicioso en el cambio por dinero o por drogas. Se trata de un tráfico provisto de cooperación militar o de seguridad, en el que se comercia armamento beligerante que termina en manos de delincuentes inescrupulosos. Es una actividad facilitada por la complicidad de agentes aduaneros y policiales. 
- La falsificación. Es otro de los medios ilegales usados por los grupos, en el cual se contrabandean y falsifican productos deportivos de marcas reconocidas (como Nike o Adidas), perfumería, cigarrillos, juguetes, electrónicos y todo lo que sea posible falsificar.

- El comercio de drogas también es nutrido gracias a países productores como Colombia, Perú, Ecuador y Bolivia, cuyos productos se llevan hacia Europa y Estados Unidos. Según Josefina Lynn (2011), las drogas son transportadas en Paraguay por el río Paraná, por vía terrestre y aéreo hacia Foz de Iguazú.

\section{Desafíos a la gobernanza}

El crimen organizado transnacional se ha convertido en un grave problema para la seguridad, ya que no solo atenta contra las instituciones democráticas y la actividad económica de los Estados, sino que, al momento de traspasar las fronteras, se convierte en un fenómeno que logra atentar contra la estabilidad y la seguridad del hemisferio (Moreno, 2015, p. 2).

Las acciones que estos grupos llevan a cabo no se realizan normalmente en el centro de las ciudades, sino que llevan sus operaciones a los espacios grises, fronteras estatales, áreas donde el Estado no llega o tiene un difícil acceso. Estos espacios se convierten en zonas propicias para la consolidación de dichos grupos criminales, que se fortalecen a través de la expansión de sus actividades y generan efectos devastadores sobre la gobernabilidad del Estado.

Existen tres factores esenciales que convierten al COT en una amenaza para los Estados. En primer lugar, los índices de violencia provocan una desventaja para el país en cuanto a la inversión extranjera directa. En segundo lugar, el aparato estatal logra perder credibilidad ante la población civil con los casos de corrupción, la inestabilidad judicial, la falta de acción para contrarrestar el crimen y la falta de garantías hacia la población más afectada.

Por último, la seguridad ciudadana se convierte en el principal problema que aqueja al país, dada la impunidad al interior del aparato judicial y su inasistencia en las zonas más afectadas por el crimen. De esta forma, se da una pérdida de legitimidad del gobierno para la población y, en consecuencia, se incrementa la violencia.

Igualmente, al incrementarse la acción criminal en los Estados, se genera conmoción entre la población con la inseguridad ciudadana e inestabilidad dentro de la región; factores que se evidencian en los altos índices de violencia, corrupción, inestabilidad económica y política, pobreza y desigualdad en los países. En este sentido, Moreno argumenta:

La importancia y gravedad del COT en algunos países del hemisferio es tal, que se han desarrollado zonas denominadas "reductos de impunidad", en los que la presencia del Estado es reemplazada en algunas ocasiones por el poder e influencia ejercido por dichos grupos criminales. (2015, p. 5) 
Es por esto que el Estado observa, desde distintas ópticas, las consecuencias de la permeabilidad del país en torno a la gobernanza. Ahora se tiene la oportunidad de que este flagelo no persista y se continúe por la vía de contrarrestar los efectos del crimen organizado transnacional, ya que eliminarlo de raíz no es una opción a corto ni mediano plazo.

Dadas las consideraciones anteriores, la implementación de políticas públicas es percibida como una alternativa a la gobernanza del Estado para la disminución de la criminalidad y el fortalecimiento del aparato institucional. Además, no se debe dejar de lado la cooperación por medios multilaterales, debido a que el hemisferio se encuentra debilitado y afectado por esta amenaza en común, y con las políticas acertadas y consensuadas es posible disminuir este fenómeno.

\section{Conclusiones}

La globalización ha complicado la identificación de los actores que perpetran las actividades delictivas y terroristas. La multiplicidad de grupos ilegales va en aumento, puesto que se han venido creando redes criminales más profundas y difíciles de reconocer en un entorno corrupto. Estos factores promueven una mayor tasa de desigualdad, pobreza y una economía poco estable.

La ilegalidad en la Triple Frontera se ha facilitado al contar con fronteras sumamente permeables y ser zona de escaza o nula vigilancia, caótica y adherida a un constante problema institucional que va desde la corrupción hasta la criminalidad. A pesar del indudable alojamiento de redes criminales como la Yakuza, de comunidades árabes, libanesas, chinas, surcoreanas y los mismos grupos delictivos de Brasil, no basta su existencia y su grado de criminalidad para probar la presencia de células terroristas en la Triple Frontera.

A su vez, la complejidad de la situación de seguridad en la región por las constantes amenazas no ha sido suficiente para que los tres países logren la construcción de un modelo de vigilancia y control eficaz. Esta situación es preocupante por la permanencia de los altos niveles de criminalidad, mientras que la cooperación entre los países se enfría a través de los años y se forja un proceso individual sin el efecto deseado de frenar el COT.

Ha existido una lucha por el dominio territorial, en la que los principales grupos criminales en Brasil — Primer Comando Capital y el Comando Vermelho- han cobrado una rápida expansión y una mejora en sus técnicas criminales, con lo cual han mermado las capacidades de control del Estado: grupos juveniles que a medida que diversificaban sus fuentes de ingresos, mejoraban su equipamiento bélico y formaban estructuras jerarquizadas. Estos grupos, hoy en día, representan una de las principales amenazas a la seguridad de la Triple Frontera.

Por otro lado, en materia de seguridad y en pro de optimizar las zonas turísticas, los gobiernos han implementado políticas migratorias, reforzamiento de seguridad aérea y controles terrestres, sin embargo, estas prácticas han sido insuficientes para lograr un mayor control de la mercancía que entra y sale. En Brasil se refuerza la seguridad aérea, en 
Argentina se refuerzan los controles migratorios, pero Paraguay queda excluido de estas salidas a los problemas institucionales. Es por esto que las políticas que se implementen deben realizarse de manera conjunta - ejemplo de ello es el Mercosur y el Comando Tripartito- - pero para que sean efectivas deben ejecutarse con mayor frecuencia y fuerza: una cooperación con más fortalezas que debilidades.

El control en la zona fronteriza, como se ha podido evidenciar, carece de instrumentos alternos y es insuficiente, puesto que entre los tres países no se dispone de la cooperación en seguridad necesaria para detener o disminuir las actividades ilícitas. Es preocupante que, a través de las carreteras, lanchas, avionetas y otros medios de transporte, se crucen libremente productos de contrabando. Además, están siendo robados los equipamientos de las fuerzas de seguridad tanto militares como policiales y están siendo distribuidos en las organizaciones criminales causantes de las principales muestras de violencia urbana, que salen victoriosas e inmunes a cualquier condena carcelaria, dados sus evidentes nexos con las autoridades de vigilancia y monitoreo en las zonas fronterizas.

A lo largo del documento se evidenciaron cuatro elementos que permitieron el asentamiento de redes criminales en la Triple Frontera:

1. Las características de la región. Al contar con una frontera de escasa vigilancia, que ha tenido un importante crecimiento poblacional y una transnacionalización como consecuencia de la globalización, las bandas (con un alcance local en principio) pasaron a tener un alcance regional. Este factor es estratégico para pasar las mercancías por espacios aéreos, marítimos y terrestres, y para ampliar sus redes y su capacidad hacia el exterior.

2. Las iniciativas conjuntas son pocas, no son constantes y carecen de cooperación real, lo cual asienta el poder de las bandas criminales, que aprovechan las zonas grises o la flexibilidad del tránsito transfronterizo entre los tres Estados, ya que estos se encuentran con obstáculos y dificultades para coordinar políticas y enfrentar o mitigar los dańos que representa el COT.

3. La ausencia de controles representa una de las principales dificultades para enfrentar la ilegalidad en la Triple Frontera: la vigilancia en insuficiente o corrupta, por lo tanto, es necesaria la existencia de políticas globales y locales, así como realizar controles efectivos en la zona.

4. Por último, la corrupción ha contribuido al incremento de la ilegalidad y al asentamiento de grupos criminales. Las autoridades aduaneras en la región apoyan las redes delincuenciales y quebrantan el aparato judicial y la democracia; traen inseguridad, violencia y la ruptura del órgano legislativo para imponer leyes más duras contra las redes criminales y así realizar una judicialización efectiva y eficaz. Su actuación resulta nefasta para contrarrestar las amenazas globales en torno a la seguridad internacional. 
Las zonas fronterizas de manera histórica han sido territorios en los cuales se promueve el desarrollo de diferentes actividades ilícitas, condición que no ha sido ajena a América Latina. Esto, para nuestros territorios, se ve relacionado con características propias de ellos: la geografía muestra zonas fronterizas de tipo selvático, de difícil acceso y poco pobladas, lo que favorece el desarrollo de este tipo de actividades. En este continente, las "fronteras calientes, abandonadas o borrosas y el narcotráfico" son problemas de seguridad que "atraviesan de sur a norte el continente desde México hasta Tierra del Fuego" (Melo, 2013). Por las mismas condiciones relacionadas, en estos espacios geográficos el Estado está ausente, no ejerce su soberanía, lo que beneficia la acción de grupos delincuenciales.

Todos los anteriores elementos forman una confluencia y no actúan de forma aislada, son factores que han crecido de manera exponencial y hoy día simbolizan la incapacidad del Estado para hacer frente al COT y mitigarlo. Se trata del respeto por la soberanía nacional de Argentina, Paraguay y Brasil: a pesar de las controversias sobre el alojamiento de células terroristas y el control del territorio —según la intervención internacional—, se evidencia que es necesario una cooperación netamente regional. Se han implementado estrategias como el Plan de Cooperación y Asistencia Recíproca (2008), el Comando Tripartito (1996), un Centro Regional de Inteligencia y el Plan General de Seguridad para la Triple Frontera. En efecto, se trata de aunar esfuerzos de cooperación y coordinación entre las fuerzas de seguridad, compartir información verídica sobre el tráfico de armas, drogas o personas, realizar investigaciones sobre redes criminales que no sean encubiertas por instituciones estatales y evitar, en especial, dejar de lado a Paraguay (Ciudad del Este). Cuando se habla de cooperar, se habla de un trabajo en coordinación, con respeto por los intereses de cada uno, sin tratar de sobrepasar las capacidades del otro.

La Triple Frontera es mucho más que criminalidad y corrupción, es también turismo familiar, es naturaleza, es el medio que no rechaza sino que incentiva a los países en vías de desarrollo a salir de la pobreza, la desigualdad y de economías poco estables. Es ir por el camino del desarrollo, no de transitar por la marginación hacia la ilegalidad y, lo más importante, la Triple Frontera es un indicador de recursos naturales por preservar.

\section{Agradecimientos}

La autora agradece a la Universidad Militar Nueva Granada por su apoyo en la realización de este artículo.

\section{Declaración de divullgación}

La autora no declara ningún potencial conflicto de interés relacionado con el artículo.

\section{Financiamiento}

La autora no declara fuente de financiamiento para la realización del artículo. 


\section{Sobre la autora}

Geraldine Cuervo Ceballos. Profesional en Relaciones Internacionales y Estudios Políticos de la Universidad Militar Nueva Granada. Coordinadora de Internacionalización del Centro de Estudios en Seguridad y Paz.

\section{Referencias}

7 toneladas de marihuana, en un barco por el Río Paraná. (2016, diciembre 31). Elentrerios. Recuperado de https://www.elentrerios.com/actualidad/7-toneladas-de-marihuana-en-un-barco-por-el-rao-parana.htm.

Argentina, Instituto Nacional de Estadística y Censos (Indec). (2017). Sistema Estadístico. Recuperado de http://www.indec.gob.ar/sen.asp.

Bartolomé, M. (2002). La Triple Frontera: principal foco de inseguridad en el Cono Sur americano. Recuperado de http://www.academia.edu/2947342/_2002_La_Triple_Frontera_principal_Foco_ de_Inseguridad_en_el_Cono_Sur_americano.

Bello, D. (2013). La Triple Frontera como polo de atracción de actividades ilícitas: Condiciones endógenas institucionales e ilegalidad. Atenea (Concepción), 508, 101-120. doi: https://dx.doi.org/10.4067/ S0718-04622013000200008.

Brasil, Instituto Brasileño de Geografía y Estadística (IBGE). (2017). Projeção da população do Brasil e das Unidades da Federação. Recuperado de http://www.ibge.gov.br/home/geociencias/cartografia/ default_territ_area.shtm.

Calderón, H. (2007). Crimen organizado y terrorismo en la Triple Frontera y regiones adyacentes. Recuperado de http://www.elojodigital.com/contenido/9078-crimen-organizado-y-terrorismo-en-la-triple-frontera-y-areas-adyacentes.

Convención de Palermo. (2000). Convención de las Naciones Unidas contra la Delincuencia Organizada Transnacional. Recuperado de https://www.oas.org/csh/spanish/documentos/Convenci\%C3\%B3n\%20 de\%20Palermo\%20_ESP.pdf.

Dreyfus, P. (2005). Agenda de seguridad en el Mercosur: la Triple Frontera como "espacio de inseguridad regional”. Recuperado de http://comunidadesegura.org.br/files/DreyfusTriplefrontera.pdf.

Fogel, R. (2008). La región de la Triple Frontera: territorios de integración y desintegración. Sociologías, 20, 270-290.

Giménez, V., \& Montenegro, S. (2010). La Triple Frontera. Dinámicas culturales y procesos transnacionales. Buenos Aires: Editorial Espacio.

Guillem, P. (2014) ¿El auge de los conflictos híbridos? Recuperado de http://www.ieee.es/Galerias/fichero/docs_opinion/2014/DIEEEO120-2014_GuerrasHibridas_Guillem_Colom.pdf.

Hoffman, F. G. (2009). Hybrid vs. compound war: The Janus choice of modern war. Defining today's multifaceted conflict. Recuperado de http://www.armedforcesjournal.com/hybrid-vs-compound-war/.

Iniciativa para la Integración de la Infraestructura Regional Suramericana (IIRSA). (2005). Facilitación del transporte en los pasos de frontera en Sudamérica. Recuperado de http://www.iirsa.org/admin_iirsa_web/Uploads/Documents/pfd_ftpf2_completo.pdf.

Kaldor, M. (2001). New and old wars: Organized violence in a global era. Stanford: Stanford University Press.

La ruta de la droga que atraviesa el Río Paraná. (2016). Ahora. Recuperado de: https://ahora.com.ar/laruta-la-droga-que-atraviesa-el-rio-parana-n366658. 
Lynn, J. (2011). La amenaza terrorista en la Triple Frontera. Saarbrücken: Editorial Académica Espańola.

Melo, J. (2013). Retos de seguridad en América Latina fueron debatidos en foro en Bogotá. El País. Recuperado de http://www.elpais.com.co/judicial/retos-de-seguridad-en-america-latina-fueron-debatidos-en-foro-en-bogota.html.

Moreno, N. (2015). El crimen organizado transnacional una amenaza latente para el continente americano. Bogotá: Universidad Militar Nueva Granada.

Naím, M. (2012, mayo 5). Estados mafiosos. El País. Recuperado de https://elpais.com/internacional/2012/05/05/actualidad/1336245036_975620.html.

Organización de Estados Americanos (OEA). (2003). Conferencia especial sobre seguridad. Recuperado de https://www.oas.org/csh/ces/documentos/ce00358s06.doc.

Osorio, I. (2015). La relación entre el crimen organizado transnacional en la Triple Frontera y la política exterior de seguridad de Brasil, Argentina y Paraguay entre 1996 y 2006. Universidad Colegio Mayor de Nuestra Señora del Rosario, Bogotá, Colombia.

Paraguay, Dirección General de Estadística, Encuestas y Censos (DGEEC). (2016). Anuario estadístico del Paraguay 2014. Recuperado de http://www.dgeec.gov.py/Publicaciones/Biblioteca/anuario2014/ Anuario\%20Estadistico\%202014.pdf.

Pereira, C. (2016). Fronteiras Irmãs. Transfronteirizaçoes na bacia do prata. Porto Alegre: Editorial Ideograf.

Pérez, L. (2017, marzo 19). Pedro Juan Caballero, la ciudad paraguaya que se convirtió en la capital narco de Sudamérica. Infobae. Recuperado de: http://www.infobae.com/america/america-latina/2017/03/19/pedro-juan-caballero-la-ciudad-paraguaya-que-se-convirtio-en-la-capital-narco-de-sudamerica/.

Rabossi, F. (2014). Dinámicas económicas en la Triple Frontera (Brasil, Paraguay y Argentina). En F. Carrión, Seguridad, planificación y desarrollo en las regiones trasfronterizas (pp. 167-193). Quito: Centro Internacional de Investigaciones para el Desarrollo.

Rivas, F. (2017, abril 25). Atraco de película en Paraguay: 50 hombres roban millones de dólares en una oficina de Prosegur. El Pais. Recuperado de https://elpais.com/internacional/2017/04/24/america/1493047109_595943.html.

Rojas, F. (2016). Una amenaza a la paz y la democracia del hemisferio. Revista de Difusión y Análisis del Centro de Análisis Estratégico Ejercito del Futuro, 1, 42-51.

Secuestran 7 toneladas de marihuana a bordo de un barco en el río Paraná Guazú. (2016, diciembre 30). Clarin. Recuperado de: https://www.clarin.com/policiales/secuestran-toneladas-marihuana-bordo-barco-rio-parana-guazu_0_Byx2DYNBe.html.

Traslaviña,H. (2014, noviembre 15). Ciudad del Este: cómo opera el principal foco del contrabando en Sudamérica. La Segunda. Recuperado de http://www.lasegunda.com/Noticias/Economia/2014/11/975536/ciudad-del-este-como-opera-el-principal-foco-del-contrabando-en-sudamerica. 